\title{
OJED
}

Volume 5, Issue 1 (2020), pp. 174-179

International Journal of

Multidisciplinary Perspectives in Higher Education

ISSN: 2474-2546 Print/ ISSN: 2474-2554 Online

https://ojed.org/jimphe

\section{Moving Beyond the Statements: The Need for Action to Address Structural Racism at Predominantly White Institutions}

\author{
Monica Galloway Burke \\ Western Kentucky University, Kentucky, USA
}

\begin{abstract}
Higher education may once again be at a crossroad with the racial climate in the United States and what that means for college campuses. Consequently, institutions of higher education must commit to ensuring a supportive organizational structure for the social and psychosocial wellbeing of Black students and guaranteeing support resources for the psychological well-being of Black students. Such efforts require significant and enduring structural changes within institutions of higher education that should be ongoing and consistent.
\end{abstract}

Keywords: Black students, campus policies, equity, inclusion, racism, racial equality

As the protests for racial equality and justice unfold in the United States, so has the presence of comments filled with hateful words and ideologies regarding Black people and communities. In the news, there are reports and incidents of this type of commentary coming from incoming students, current students, as well as faculty and staff at predominantly white institutions (PWIs) who are White. Institutions of higher education have addressed these circumstances differently with some withdrawing admission and scholarships from the incoming student and some others pointing out the fact that the first amendment limits institutional action while 
simultaneously condemning hatred. Of course, racially motivated biases and incidents have occurred on college campuses prior; but now, people are more vigilant and willing to share such stories with the public. In fact, according to National Center for Education Statistics (NCES) data, of the total reported on campus hate crimes in 2016, race was the most frequent category of motivating bias associated with the three most common types of hate crimes reported-vandalism, intimidation, and simple assaultaccounting for $38 \%$ of reported vandalisms, $40 \%$ of reported intimidations and $42 \%$ of reported simple assaults (Musu et. al, 2019). The current challenge for higher education institutions is how to more effectively address these actions and behaviors on campus and the associated psychosocial consequences on those most impacted. To begin, policies and actions that adequately address racially motivated campus incidents, discrimination, and campus unrest as well as provide psychosocial support and a safe environment to Black faculty, staff and students on campus have to be paramount.

The nationwide protests once again present our country - and each one of us - with the need to confront the continuing legacy of slavery and segregation in America and our interiority that sustains racism and hatred. Racism became institutionalized in the culture and structure of the United States through a process of legalization that systematically subjugated and exploited Africans who were enslaved, regulating them to a subordinate position that included marginalization and discrimination (Tourse et al., 2018). Each new generation of African Americans inherited this enduring framework of racial inequality and enduring racism that has infiltrated their family dynamics, economics, generational wealth, education, and social capital. Damages done to African Americans did not end with slavery, but persisted for another one hundred years in the form of legal segregation to present-day discrimination, which also included violence and coercion from Whites, an unjust judicial system, income and economic losses, and oppression (Feagin, 2004). The fight for civil rights and legal equality of African Americans -petitioning the courts and the federal government for relief against the discriminatory treatment of private or state actors (Loury, 1998) - may have changed separate but equal, removed Jim Crow laws and the Black Codes, and set parameters for fair employment, but it did not change mindsets and the discriminatory treatment of African Americans. The election of Donald Trump in 2016 only highlighted these preexisting hostile attitudes toward African Americans, leading to their increased levels of stress and anxiety (Williams \& Medlock, 2017).

What must not be missed is the fact that PWIs will now more than likely have to deal with requests for more action toward racial equality from Blacks and allies within the campus community even more so than in the past, and will have to move beyond platitudes and simply talking around the edges about racial equality and racism. Higher education is often viewed as 
a producer of knowledge and an utopian space beyond racial inequality (Johnson \& Joseph-Salisbury, 2018); however, "academe is deeply implicated in maintaining and perpetuating the conditions that give rise to racial microaggressions" (p. 143) and is a "site of oppression, resistance, and transformation" (Stockdill \& Danaco, 2012, p. 1) like other institutions. Ultimately, we must not forget that higher education was not set up to welcome diversity and inclusion and although change has occurred, that change came with excluded groups fighting to gain entry that included lawsuits, protesting, sit-ins, sleep-ins, and hunger strikes (Simmons, 2002).

Higher education institutions should clearly acknowledge their commitment to become actively engaged in efforts to ensure racial equality and justice in all areas of society, but specifically on campus. This commitment should be two-fold - ensuring a supportive organizational structure for the social and psychosocial well-being of Black students and guaranteeing support resources for the psychological well-being of Black students. Having statements and institutional missions that encourage fair treatment and respect for everyone and an acceptance of differences while working toward greater inclusion is a start. However, such statements do not negate previous incidents and existing unwelcoming environments. What matters most is what action will take place now after a declaration of awareness about inequality, biases, and discrimination for Blacks in the campus community.

Although change can begin with dialogue, actions must be deliberate that support Black students, including a supportive campus climate where acts of racism and discrimination are not normalized, and the students have a voice. As the relationship between racial bias, attitudes, and perceptions is directly related to the climate and culture of an organization, diversity goals, equity, inclusion, and social justice must be integrated into the campus culture to build a more positive campus climate for Black students. The cultures and structures for accountability to diversity goals and the roles in advancing (or maintaining) disparities (Kezar \& Eckel, 2002) and the configuration of external influences, structural characteristics of the institution and group relations, and institutionalized ideologies (Hurtado, 1992) must also be examined.

Institutions should also invest in efforts to establish a support system to address the psychological and psychosocial consequences of students experiencing and witnessing racism and discrimination. Seeing and hearing disparaging comments about a dimension of who you are, of which you cannot hide, can have a detrimental impact on the psychological and psychosocial well-being of individuals, which must be taken into account when addressing structural racism in higher education. Currie and colleagues (2012) found that the most common psychological reactions for students experiencing discrimination was to feel a sense of helplessness and hopelessness. As reiterated by a student participant in their study, "Being a 
minority is like being in a cage with no help. Sometimes it's better to accept than to fight" (Currie et al., 2012, p. 622). The psychological stress students experiencing racism and discrimination on the college campus can be perceived as taxing or exceeding their resources and endangering their wellbeing (Lazarus \& Folkman, 1984). Racial battle fatigue (RBF) has been used to describe such experiences of students of color in postsecondary settings, which affirms that the cumulative, negative effect of racial microaggressions causes them to often become physically and emotionally drained (Smith, 2009). Higher levels of perceived racial discrimination have also been related to lower levels of psychological adjustment (Jackson et al., 2012). Therefore, institutions of higher education should proactively develop culturally competent, accommodating, and multi-faceted efforts that can support Black students who are dealing with psychological stress and distress due to what is occurring in the news and on campus related to race relations and discrimination. Such efforts can include providing access to culturally competent counselors and spaces Black students can share their thoughts freely and safely; having processes in place when students experience discrimination that will thoroughly investigate reported issues; instituting mandatory initiatives that can help prepare all members of the campus to learn about and confront racial inequity and injustice through a systemic approach; and creating opportunities for all students to engage in cross-racial interactions as well as cultural experiences and exploration to broaden their worldview. The goal is to create a campus racial climate that is welcoming for all students and where all students can benefit from racial pluralism (Smith et al., 2007). Key institutional agents' willingness to provide students with holistic support may be a critical factor in the success of racial minority students in college and this support might be critical because it can foster racial minority students' trust in the agents' ability and desire to help them to find the necessary information and support to resolve their issues (Museus \& Neville, 2012). Ultimately, the campus community should be aware of and prepare to address the psychological and psychosocial impact that racism, discrimination and racial tensions cause and the consequences when there is a lack of institutional support for those most impacted.

Two factors perpetuate racism and inequality - one is our internal dimensions and the other is the institutional structures, such as in higher education. Higher education can play a role in addressing both. As PWIs move forward to address racial inequities and discrimination and offer support to those most affected by them, many must first begin with admitting that past efforts to address racism on their campuses, although often well meaning, have been focused on superficial changes (e.g., having diversity committees without money or influence, adding diversity to the strategic plan and student evaluations, and including inclusion in mission statements) while sustaining the status quo. 
Hosting listening sessions, instituting a special task force, implementing efforts to increase the recruitment of Black students, asking the campus community to volunteer to participate in sensitivity and diversity training, and conducting a climate survey without follow-up are common reactions to addressing requests for improving campus climate for racial minorities that only scratch the surface of what is needed. Purposeful and decisive actions are needed that hold individuals accountable and illustrate power to enact and support real change. What is needed will have to move beyond just implementing reactionary measures to a controversial racial incident that comes under public scrutiny, which loses interest and funding once the spotlight is gone or a new issue arises. Leaders will need to participate in real work toward equality and equity and not expect Black faculty, staff, and student leaders to take the lead, but to be a part of the decision-making process. However, as Brown (2004) speculated, even if people are in agreement with the principles of diversity, they may be reluctant to change and, in practice, are content to leave things as they are. This school of thought can no longer be an option if campus leaders desire to meet the current challenges and make a real change. More than ever, there is a need for significant and enduring structural changes within institutions of higher education.

\section{References}

Brown, L. I. (2004). Diversity: The challenge for higher education. Race Ethnicity and Education, 7, 21-34. https://doi.org/10.1080/1361332042000187289

Currie, C. L., Wild, T. C., Schopflocher, D. P., Laing, L., \& Veugelers, P. (2012). Racial discrimination experienced by Aboriginal University students in Canada. Canadian Journal of Psychiatry, 57(10), 617-625. https://doi.org/10.1177/070674371205701006

Feagin, J. (2004). Documenting the costs of slavery, segregation, and contemporary racism: Why reparations are in order for African Americans. Harvard Black Letter Law Journal, 20, 49-81.

Hurtado, S. (1992). The campus racial climate: Contexts of conflict. The Journal of Higher Education, 63(5),

539-569. https://doi.org/10.1080/00221546.1992.11778388

Jackson, K. F., Yoo, H. C., \& Guevarra, R., Jr. (2012). Role of identity integration on the relationship between perceived racial discrimination and psychological adjustment of multiracial people. Journal of Counseling Psychology, 59(2), 240-250. https://doi.org/10.1037/a0027639

Johnson, A. \& Joseph-Salisbury, R. (2018) 'Are you supposed to be in here?' Racial microaggressions and knowledge production in higher Education. In J. Arday \& H. S. Mirza (Eds.), Dismantling race in higher education: Racism, whiteness and decolonising the academy (pp. 143-160). Palgrave Macmillan. https://doi.org/10.1007/978-3-319-60261-5_8

Kezar, A., \& Eckel, P. D. (2002). The effect of institutional culture on change strategies in higher education: Universal principles or culturally responsive 
concepts? The Journal of Higher Education, 73(4), 435-460. https://doi.org/10.1080/00221546.2002.11777159

Lazarus, R. S. \& Folkman, S. (1984). Stress, appraisal, and coping. Springer.

Loury, G. C. (1998, March 1). An American Tragedy: The legacy of slavery lingers in our cities' ghettos. The Brookings Institution. Retrieved September 24, 2020, from https://www.brookings.edu/articles/an-american-tragedy-thelegacy-of-slavery-lingers-in-our-cities-ghettos/

Musu, L., Zhang, A., Wang, K., Zhang, J., and Oudekerk, B.A. (2019). Indicators of school crime and safety: 2018 (NCES 2019-047/NCJ 252571). National Center for Education Statistics, U.S. Department of Education, and Bureau of Justice Statistics, Office of Justice Programs, U.S. Department of Justice. Washington, DC.

Museus, S. D., \& Neville, K. M. (2012). Delineating the ways that key institutional agents provide racial minority students with access to social capital in college. Journal of College Student Development, 53(3), 436-452. https://doi.org/10.1353/csd.2012.0042

Simmons, G. Z. (2002). Racism in higher education. University of Florida Journal of Law \& Public Policy, 14(1), 29-44.

Smith, W. A. (2009). Campus wide climate: Implications for African American students. In L. Tillman (Ed.), A handbook of African American education (pp. 297-309). Sage. https://doi.org/10.4135/9781412982788.n18

Smith, W. A., Yosso, T. J., \& Solórzano, D. G. (2007). Racial primes and black misandry on Historically White Campuses: Toward critical race accountability in educational administration. Educational Administration Quarterly, 43(5), 559-585. https://doi.org/10.1177/0013161X07307793

Stockdill, B. C., \& Danico, M. Y. (2012). The ivory tower paradox: Higher education as a site of oppression and resistance. In B. C. Stockdill \& M. Y. Danico (Eds.), Transforming the ivory tower: Challenging racism, sexism, and homophobia in the academy (pp. 1-30). University of Hawaii Press. https://doi.org/10.21313/hawaii/9780824835262.003.0001

Tourse, R. W. C., Hamilton-Mason, J., \& Wewiorski, N. J. (2018). Systemic racism in the United States Systemic: Scaffolding as social construction. Springer. https://doi.org/10.1007/978-3-319-72233-7

Williams, D. R., \& Medlock, M. M. (2017). Health effects of dramatic societal events-Ramifications of the recent presidential election. The New England Journal of Medicine, 376, 2295-2299. https://doi.org/10.1056/NEJMms1702111 